\title{
Épocas e Extensões do Período de Convivência das Plantas Daninhas Interferindo na Produtividade da Cultura do Milho (Zea mays) ${ }^{1}$
}

\author{
Times and Extension of Weed Coexistence Period of Weeds Interfering in Corn (Zea mays) Yield
}

\author{
KOZLOWSKI, L.A. ${ }^{2}$, KOEHLER, H.S. ${ }^{3}$ e PITELLI, R.A. ${ }^{4}$
}

\begin{abstract}
RESUMO - Foi conduzido na Fazenda Experimental Gralha Azul/PUCPR, município de Fazenda Rio Grande, PR, um experimento de campo com o objetivo de avaliar o efeito de diferentes épocas e extensões do período de convivência das plantas daninhas interferindo na produtividade da cultura do milho. O delineamento experimental utilizado foi o de blocos ao acaso, em esquema fatorial $4 \times 5+2$, com quatro repetições. Os tratamentos foram: quatro períodos iniciais de controle (0-0, 0-7, 0-14 e 0-21 DAE) e cinco períodos em que se reiniciou o controle das plantas daninhas, prolongando-se até a colheita: 28, 42, 56, 70 e 84 DAE, e mais duas testemunhas, uma com e outra sem controle das plantas daninhas durante todo o ciclo da cultura. O experimento foi instalado em sistema de plantio direto. Foram avaliados o período anterior à interferência (PAI), a existência do periodo anterior à interferência subsequente (PAI-S), o início do período crítico de competição (PCC) e a comunidade infestante. Quando o período inicial de controle da comunidade infestante foi de O-O dia, o PAI foi de 9 DAE do milho, porém, com periodos iniciais crescentes de controle (0-7, 0-14 e 0-21 DAE), houve aumento no PAI em relação a O-O dia de controle inicial, evidenciando assim a existência do PAI-S, que foi de 17, 24 e 28 DAE do milho, respectivamente. Dessa forma, o início do PCC começa a partir do final do PAI e PAI-S, caracterizando-se pelo período durante o qual é imprescindivel a realização do controle da comunidade infestante para que não ocorra redução significativa na produtividade de grãos do milho. A convivência com as plantas daninhas durante todo o ciclo da cultura reduziu a sua produtividade em 15\%, em relação à testemunha livre de competição. No levantamento da comunidade infestante foram encontradas nove espécies, inseridas em sete familias botânicas. Verificou-se redução na densidade e massa seca das plantas daninhas que conviveram com o milho, em relação àquelas que cresceram na ausência da cultura, evidenciando assim um efeito supressivo do milho sobre as plantas infestantes.
\end{abstract}

Palavras-chave: comunidade infestante, interferência, período crítico de competição, rendimento do milho.

ABSTRACT - Q field experiment was carried out at the Gralha Azul Experimental Farm/PUCPR, in the municipality of Fazenda Rio Grande-PR, to evaluate the effect of different times and coexistence extension periods of weeds interfering in corn yield. The experiment was arranged in a complete randomized complete block design and the treatments in a 4x5+2 factorial, with four replications. The treatments were as follows: four initial weed control periods (0-0, 0-7, 0-14 and 0-21 DAE) and five restarted weed control periods until the harvest $(28,42,56,70$ and 84 DAE) and two checks, weedy and weed-free. The experiment was carried out under a no-till system. The period prior to weed interference (PBWI), the start of the critical period of weed interference (CPWI) and the infesting community were evaluated. When the initial weed control period was $0-O$ day, the PPWI was at 9 DAE of corn; however, with increasing initial weed control periods (0-7, 0-14 and 0-21 DAE) the period prior to weed interference inncreased in relation to $0-0$ day of the initial weed control,

1 Recebido para publicação em 26.5.2008 e na forma revisada em 15.5.2009.

Parte da tese do primeiro autor apresentada à UFPR para obtenção do título de Doutor em Agronomia (Produção Vegetal).

2 Prof. Adjunto, Doutor, Pontifícia Universidade Católica do Paraná, Curitiba-PR, <luiz.kozlowski@pucpr.br>; ${ }^{3}$ Prof. Adjunto, Doutor, Dep. de Fitotecnia e Fitossanitarismo da UFPR, Curitiba-PR; ${ }^{4}$ Prof. Titular, Doutor, Dep. de Biologia Aplicada à Agropecuária da UNESP, Jaboticabal-SP.

Planta Daninha, Viçosa-MG, v. 27, n. 3, p. 481-490, 2009 
evidencing the existence of PPWI-S of 17, 24 and 28 DAE of corn, respectively. Thus CPWI initiates at the end of PPWI-S, the period when weed control is indispensable to prevent a significant reduction in corn yield. Coexistance with the weeds throughout the crop cycle reduced yield in 15\%, compared to the weed-free check. Nine species of seven botanical families were assessed in the infesting community. Reduced density and dry mass were verified in the weeds that coexisted with corn, compared to those that grew without it, thus evidencing a suppressive effect of corn over the infesting plants.

Keywords: weeds, interference, critical period of weed interference, corn yield.

\section{INTRODUÇÃO}

O milho (Zea mays) é um dos principais cereais cultivados no mundo, fornecendo produtos para alimentação humana e animal e matéria-prima para a indústria. No Brasil, a cultura ocupa posição significativa na economia, em decorrência do valor da produção agropecuária, da área cultivada e do volume produzido, especialmente nas regiões Sul, Sudeste e Centro-Oeste (Glat, 2002). Mesmo apresentando altos indices de produtividade em algumas lavouras que adotam maior nivel tecnológico, a cultura está sujeita a fatores bióticos e abióticos que interferem na sua produtividade final. Entre os fatores bióticos, destaca-se a interferência das plantas daninhas - reflexo tanto da ausência quanto da ineficiência do controle.

As perdas na produtividade do milho ocasionadas pela interferência das plantas daninhas podem atingir niveis elevados. Dependendo do tempo e da intensidade de convivência, os efeitos da interferência são irreversíveis, não havendo recuperação do desenvolvimento ou da produtividade da cultura após a retirada do estresse causado pela presença das plantas daninhas (Kozlowski, 2002). A redução da produtividade do milho devido à interferência estabelecida pelas plantas daninhas pode variar entre 10 e $90 \%$ (Wilson \& Westra, 1991; Spader \& Vidal, 2000b; Harrison et al., 2001; Massinga et al., 2001; Hellwig et al., 2002; Kozlowski, 2002; Cathcart $\&$ Swanton, 2004; Alford et al., 2005; Cox et al., 2006; Williams, 2006), dependendo do grau de interferência, que é dependente de fatores ligados à cultura, à comunidade infestante e ao ambiente, e da época e duração do período de convivência entre a planta daninha e a cultura (Pitelli, 1985).
Com relação à época e duração da convivência entre cultura e plantas daninhas, Pitelli \& Durigan (1984) definiram o período anterior à interferência (PAI), o período total de prevenção da interferência (PTPI) e o período crítico de prevenção da interferência (PCPI). O PCPI caracteriza-se pelo período durante o qual é imprescindivel realizar o controle das plantas daninhas. Dessa forma, em termos de manejo de plantas daninhas, o PAI torna-se o período de maior importância do ciclo cultural, a partir do qual a produtividade é significativamente prejudicada. Este período define o período ideal para o controle das plantas daninhas em pós-emergência, pois, além de não alterar a produtividade, as plantas daninhas teriam mobilizado uma quantidade de nutrientes que seriam gradativamente devolvidos ao sistema e colocados à disposição da cultura, além dos benefícios da cobertura morta (Pitelli, 1985). No entanto, o conhecimento deste período sempre teve uma conotação teórica, pois muitas vezes o seu final era posterior à época ideal de aplicação do herbicida em pósemergência para controle das plantas daninhas ou da fase em que este não provocava efeitos de fitointoxicação na planta cultivada.

Recentemente, com a introdução das culturas geneticamente modificadas para tolerância aos herbicidas não seletivos e sem ação residual no solo, como o glyphosate, pela primeira vez no controle químico a extensão do PAI poderá ser explorada em áreas em que a comunidade infestante não apresente espécies de difícil controle para o produto utilizado em fase mais avançada do ciclo de desenvolvimento. Com as grandes infestações de plantas daninhas que ocorrem em algumas regiões do Brasil, os valores do PAI são baixos e o controle deve ser realizado numa fase bastante precoce do ciclo da cultura. Nesse sentido, o 
uso de herbicidas sem efeito residual permite que a comunidade infestante, após um novo fluxo de emergência, se reinstale imediatamente após o controle anterior. Dependendo da densidade do mato, da intensidade de crescimento das populações de plantas daninhas e das condições do sombreamento promovidas pela cultura, o crescimento da comunidade infestante poderá ser intenso a ponto de interferir na produtividade da cultura e produzir um segundo PAI, chamado de período anterior à interferência subsequente (PAI-S), sendo este o período desde o controle das plantas daninhas até o momento em que a nova comunidade infestante (reinfestação) passa a interferir na produtividade da cultura (Pitelli, 2006).

A definição das situações em que haverá o PAI-S e em quais delas este período será precoce ou tardio no restante do ciclo da cultura é fundamental para o planejamento do número e épocas de aplicação de herbicidas não seletivos à cultura e sem ação residual ou do estabelecimento de combinações de produtos ou estratégias de manejo. Assim, o objetivo deste trabalho foi avaliar os efeitos de diferentes épocas e extensões dos períodos de convivência das plantas daninhas interferindo na produtividade da cultura do milho.

\section{MATERIAL E MÉTODOS}

O trabalho experimental de campo foi realizado no ano agrícola de 2005/06 na Fazenda Experimental Gralha Azul (FEGA), da Pontificia Universidade Católica do Paraná, município de Fazenda Rio Grande-PR, situada na latitude de $25^{\circ} 37^{\prime} 32^{\prime \prime}$, longitude de $49^{\circ} 15^{\prime}$ $29^{\prime \prime}$ e a 900 metros de altitude. O experimento foi instalado em uma área sob sistema de plantio direto, após a dessecação da vegetação. Foi realizada a semeadura do milho em 22 de novembro e emergência em 30 de novembro de 2005 , com adubação de $350 \mathrm{~kg} \mathrm{ha}^{-1}$ do formulado $10-20-20+0,5 \%$ de $\mathrm{Zn}$, utilizando-se o híbrido DKB 214 e espaçamento entrelinhas de $0,80 \mathrm{~m}$. Quando o milho atingiu o estádio fenológico V1, ou seja, uma folha totalmente expandida, foi realizado o desbaste manual de forma a uniformizar a população de plantas para 65.000 plantas ha-1 . A adubação de cobertura foi feita no estádio fenológico V4, aplicando-se $135 \mathrm{~kg} \mathrm{ha}^{-1}$ de nitrogênio, na forma de ureia; ela foi realizada manualmente, visando maior precisão da aplicação, que foi realizada lateralmente a $15 \mathrm{~cm}$ da linha do milho. Os demais tratos culturais foram aqueles necessários para que a cultura se desenvolvesse normalmente.

O delineamento experimental utilizado foi o de blocos ao acaso com quatro repetições, e os tratamentos foram dispostos em esquema fatorial $4 \times 5+2$, de forma que os tratamentos avaliados foram resultados da combinação de quatro niveis do fator periodos iniciais de controle: 0-0, 0-7, 0-14 e 0-21 dias após a emergência (DAE) e cinco níveis do fator épocas para o reinício do controle das plantas daninhas: $28,42,56,70$ e $84 \mathrm{DAE}$, mais duas testemunhas, uma com e outra sem controle das plantas daninhas durante todo o ciclo da cultura.

A parcela experimental foi composta por quatro linhas de milho com 7,0 m de comprimento e espaçadas entre si de $0,80 \mathrm{~m}$, perfazendo $22,4 \mathrm{~m}^{2}$ de área total. Para fins de avaliação, foram consideradas como área útil das parcelas as duas linhas centrais com 6,0 m de comprimento, totalizando $9,6 \mathrm{~m}^{2}$. A remoção das plantas daninhas das parcelas experimentais, durante os diferentes períodos de controle, foi realizada por meio de capina química, mediante o uso de um pulverizador costal com proteção lateral de bico (chapéude-napoleão), para aplicação em jato dirigido entrelinhas, usando uma calda de paraquat $\left(200 \mathrm{~g} \mathrm{~L}^{-1}\right)$ a $2 \%$, tantas vezes quantas foram necessárias para manter a cultura no limpo durante os períodos estipulados.

A comunidade infestante foi avaliada ao final de cada periodo de convivência com o milho $(28,42,56,70$ e $84 \mathrm{DAE})$, sendo feita a identificação, quantificação e coleta de todas as plantas daninhas presentes em $0,25 \mathrm{~m}^{2}$ central, na área útil de cada parcela experimental. As plantas daninhas foram separadas em monocotiledôneas e dicotiledôneas, para posterior secagem em estufa de circulação forcada de ar a $70^{\circ} \mathrm{C}$ até peso constante e pesagem em balança de precisão de $0,01 \mathrm{~g}$, para determinação da massa seca acumulada da parte aérea das plantas infestantes $\left(\mathrm{g} \mathrm{m}^{-2}\right)$. Em duas faixas laterais com 3,2 m de largura cada uma, ou seja, quatro linhas de semeadura, uma de cada lado, ao longo da área experimental, onde as plantas daninhas se desenvolveram livremente sem a interferência 
das plantas de milho, pois foi desligado o sistema de distribuição de sementes, foram realizadas a coleta, contagem, identificação e separação em monocotiledôneas e dicotiledôneas das plantas daninhas presentes em uma área de $0,25 \mathrm{~m}^{2}$ no final de cada periodo de convivência $(28,42,56,70$ e $84 \mathrm{DAE})$, sendo realizadas quatro repetições para cada época de amostragem. Posteriormente foi realizada a secagem em estufa de circulação forçada de ar a $70{ }^{\circ} \mathrm{C}$ até peso constante e pesagem em balança de precisão de $0,01 \mathrm{~g}$, para determinação da massa seca acumulada da parte aérea das infestantes $\left(\mathrm{g} \mathrm{m}^{-2}\right)$, que foram comparadas com a massa seca acumulada pelas plantas infestantes que conviveram com o milho nos mesmos períodos, avaliando-se assim a capacidade competitiva do milho sobre as plantas infestantes.

A colheita do milho foi realizada aos $135 \mathrm{DAE}$, e o rendimento de grãos foi avaliado na colheita das espigas da área útil das parcelas experimentais. Após a coleta das espigas foi realizada a debulha, e os grãos foram pesados para o cálculo do rendimento da cultura, em gramas por parcela, sendo os valores corrigidos para $13 \%$ de umidade e transformados em $\mathrm{kg} \mathrm{ha}{ }^{-1}$.

Para determinação do período anterior à interferência (PAI), período anterior à interferência subsequente (PAI-S) e início do período crítico de prevenção da interferência (PCPI), os dados dos rendimentos do milho obtidos nos diferentes períodos de convivência com as plantas daninhas foram ajustados a um modelo de regressão não linear, segundo o modelo logístico, usando o programa TableCurve $2 \mathrm{D}$ v.5.01, conforme a equação 1 :

$$
y=a+\frac{b}{\left[1+\left(\frac{x}{c}\right)^{d}\right]}
$$

Equação 1

em que $y$ : rendimento de grãos; $x$ : dias após a emergência do milho; e $a, b, c$ e $d$, coeficientes do modelo, de modo que $a$ é o rendimento minimo, $b$ é a diferença entre o rendimento máximo e o mínimo, representando a perda de rendimento, $c$ é tempo em dias em que ocorrem $50 \%$ de resposta no rendimento de grãos e $d$ é a declividade da curva. O início do período crítico de competição, identificado pelo final do período anterior à interferência, foi determinado tolerando-se uma redução máxima aceitável de produção de 5\% em relação àquela obtida nas parcelas mantidas no limpo durante todo o ciclo (Hall et al., 1992; van Acker et al., 1993). Tem sido sugerido um percentual máximo tolerável de perdas de rendimento de grãos em milho de 5\% (Hall et al., 1992), o qual tem sido usado na literatura como um valor hipotético para um limite de dano econômico em milho (Knezevic et al., 1994). Além disso, embora arbitrariamente escolhido, o nivel de $5 \%$ de perdas de rendimento é um provável valor entre aquele aceitável pelo produtor e o requerido para detecção de diferenças estatísticas na produção (Evans et al., 2003a).

\section{RESULTADOS E DISCUSSÃO}

No levantamento da comunidade infestante foram identificadas sete famílias botânicas, e as espécies de plantas daninhas que ocorreram na área experimental foram: papuã (Brachiaria plantaginea, BRAPL), capim-colchão (Digitaria horizontalis, DIGHO), capim-péde-galinha (Eleusine indica, ELEIN), nabiça (Raphanus raphanistrum, RAPRA), ançarinhabranca (Chenopodium album, CHEAL), picãobranco (Galinsoga parviflora, GASPA), caruru (Amaranthus retroflexus, AMARE), leiteiro (Euphorbia heterophylla, EPHHL) e guanxuma (Sida rhombifolia, SIDRH). Todas as espécies são comuns em áreas de cultivo de milho, sendo consideradas ruderais, pois são encontradas em ambientes altamente perturbados, porém produtivos, exibindo características de rápido ciclo de desenvolvimento e elevada alocação de recursos a favor de estruturas reprodutivas, com grande capacidade de produção e dispersão de diásporos com elevada persistência no banco de sementes do solo (Radosevich \& Holt, 1984).

Na Figura 1 é apresentado o acúmulo de massa aérea seca pela comunidade infestante na cultura do milho em função dos diferentes periodos iniciais e de reinício de controle e na área lateral sem milho, onde as plantas daninhas se desenvolveram livremente sem a interferência da cultura. Verifica-se nessa igura que, aos $28 \mathrm{DAE}$ do milho, os acúmulos de massa seca aérea das plantas daninhas que ocorreram nos diferentes períodos iniciais 
de controle e na faixa lateral sem milho foram muito semelhantes; contudo, a partir desse ponto evidencia-se um efeito supressivo do milho no crescimento e desenvolvimento das plantas daninhas, até os $84 \mathrm{DAE}$. O acúmulo máximo de matéria seca das plantas daninhas foi de 240,7 $\mathrm{g} \mathrm{m}^{-2}$, que ocorreu aos $84 \mathrm{DAE}$ para o grupo de tratamentos em que o período inicial de controle foi de 0-O DAE da cultura. Para os grupos de tratamentos com período inicial de controle de 0-14 e 0-21 DAE, o maior acúmulo de matéria seca também ocorreu aos $84 \mathrm{DAE}$, ao passo que, para o de 0-7 DAE, o maior acúmulo de massa ocorreu aos $70 \mathrm{DAE}$ do milho. Verifica-se que aos 84 DAE houve redução gradativa no acúmulo de matéria seca das plantas daninhas à medida que se aumentou o período inicial de controle de $0-0$ para 0-21 DAE.

Para a área lateral sem milho, o acúmulo máximo de massa seca aérea das plantas daninhas ocorreu aos 84 DAE com 767,2 $\mathrm{g} \mathrm{m}^{-2}$, correspondendo a 3,2 vezes mais $(320 \%)$ massa seca acumulada quando comparado ao do grupo de tratamentos com período inicial de controle de 0-O DAE, evidenciando assim um efeito supressivo do milho sobre o crescimento e desenvolvimento da comunidade infestante, devido a uma maior competição interespecífica pelos fatores essenciais ao crescimento (água, luz, nutrientes e $\mathrm{CO}_{2}$ ). Os resultados mostram que o aumento no período inicial livre ou de controle das plantas daninhas provoca redução bem definida na massa seca (Figura 1) e na densidade das plantas infestantes (Figura 2), visto que esse periodo pode estender-se além da época quando a maioria das plantas daninhas em estudo tipicamente emerge e, também, pelo fato de que há um menor tempo para que a comunidade infestante acumule massa até a colheita da cultura, corroborando os resultados obtidos por van Acker et al. (1993).

A competição exercida pela cultura pode ser usada na minimização do crescimento das plantas daninhas, bem como no aumento da mortalidade destas, diminuindo desse modo as perdas de produtividade (Mortensen et al., 2000). Assim, o manejo na época de semeadura da cultura, após a dessecação da cobertura vegetal, no sistema de semeadura direta, pode influenciar a competitividade da cultura em relação às plantas daninhas. Uma vez que se consiga estabelecer a cultura em condições mais favoráveis, ela pode assumir uma posição dominante na comunidade e suprimir o crescimento das demais espécies. É importante salientar que a competição exercida pela cultura é uma das ferramentas mais eficientes na redução do crescimento das plantas daninhas e fundamental nos programas de manejo integrado dessas plantas.

Na Figura 2 são apresentadas as densidades das plantas daninhas em função dos diferentes períodos iniciais e de reinício do controle. Verifica-se que houve a partir dos 42 DAE tendência de redução do número de

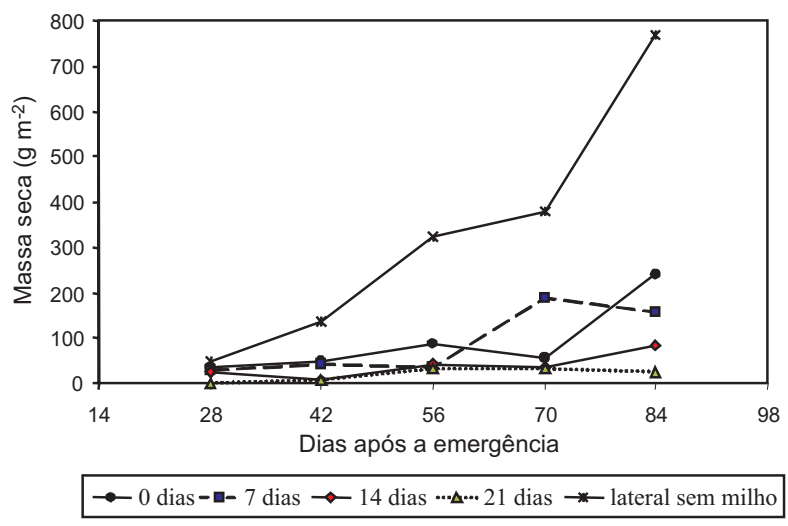

Figura 1 - Variação temporal de massa seca aérea acumulada pela comunidade infestante na cultura do milho, após períodos iniciais e de reinício de controle. FEGA/PUCPR, Fazenda Rio Grande-PR, 2005/06.

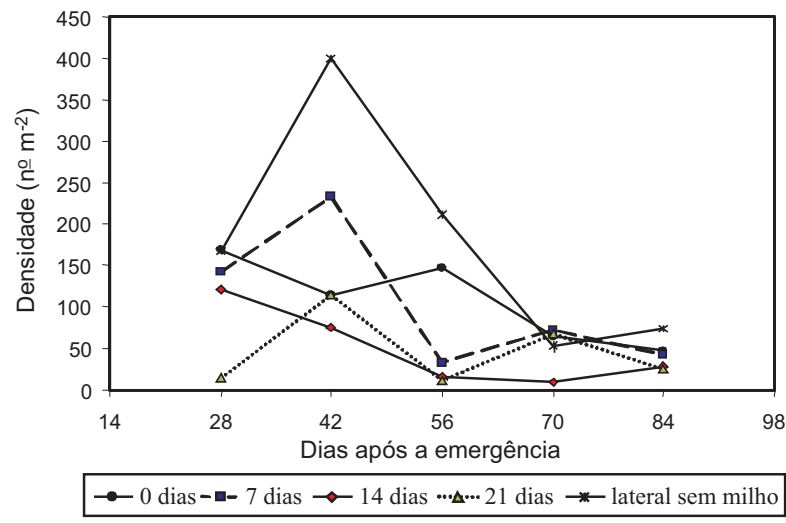

Figura 2 - Variação temporal da densidade de plantas daninhas na cultura do milho, após períodos iniciais e de reinício de controle. FEGA/PUCPR, Fazenda Rio Grande-PR, 2005/06 
plantas infestantes em todos os tratamentos, inclusive na faixa lateral sem milho. As menores densidades ocorreram aos $84 \mathrm{DAE}$, com 47, 42, 28 e 25 plantas $\mathrm{m}^{-2}$ para os períodos iniciais de controle de 0-0, 0-7, 0-14 e 0-21 DAE, respectivamente. Na faixa lateral sem milho, a densidade foi de 73 plantas $\mathrm{m}^{-2}$ aos $84 \mathrm{DAE}$. Esse valor é $1,6 \mathrm{vez}$ maior $(160 \%)$ do que a densidade dos tratamentos com controle inicial de 0-0 DAE, novamente evidenciando o efeito supressivo do milho sobre a comunidade infestante.

A variação temporal dos valores de massa seca aérea acumulada e densidade das plantas daninhas se deve ao fato de que, à medida que aumentou o crescimento das plantas daninhas, especialmente daquelas que germinaram e emergiram no início do ciclo do milho, intensificou-se a competição interespecífica e intraespecífica. Desse modo, as plantas daninhas mais altas e desenvolvidas tornaram-se dominantes, ao passo que as menores foram suprimidas ou morreram, justificando, assim, a redução da densidade das infestantes com o aumento da massa seca das plantas daninhas nos estádios mais avançados de desenvolvimento do milho. Esses resultados mostram que um controle inicial da comunidade infestante é importante para reduzir a densidade das espécies infestantes e sua capacidade de acúmulo de matéria seca e de mobilização de recursos do meio e, portanto, seu poder de interferência competitiva sobre a cultura do milho.

Nas Figuras 3, 4, 5 e 6 são apresentadas as curvas de tendência do rendimento de grãos do milho em função dos diferentes períodos iniciais e de reinício de controle das plantas daninhas, e, na Tabela 1 , os valores dos coeficientes obtidos pelo ajuste do modelo logístico aplicado ao rendimento de grãos do milho.

De acordo com a tendência das curvas obtidas para os tratamentos com diferentes periodos iniciais e de reinício de controle das plantas daninhas (Figuras 3, 4, 5 e 6), observase que a redução na produtividade do milho em função dos diferentes periodos de convivência apresentou uma resposta sigmoidal, indicando que na fase inicial, de menor inclinação e mais suave da curva, a interferência das plantas daninhas foi baixa, pelo fato de as

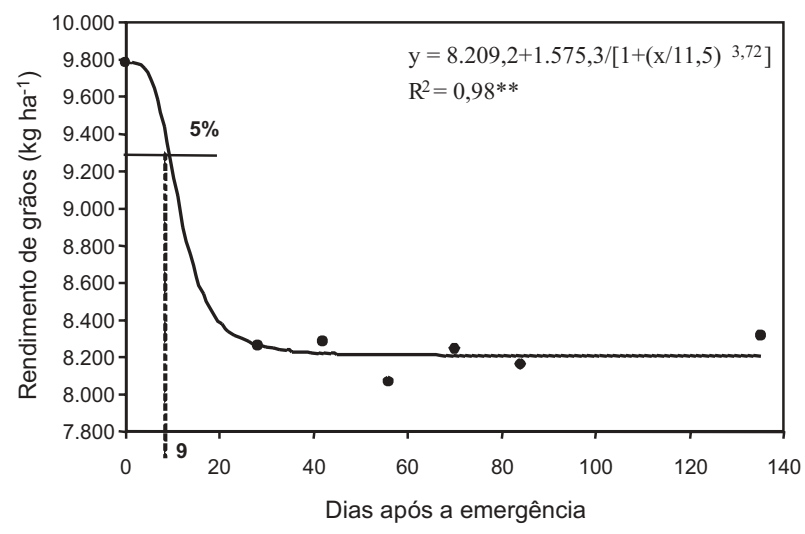

Figura 3 - Efeito do período de 0-0 dia de controle inicial e dos diferentes períodos de reinício de controle das plantas daninhas sobre o rendimento de grãos na cultura do milho. FEGA/PUCPR, Fazenda Rio Grande-PR, 2005/06

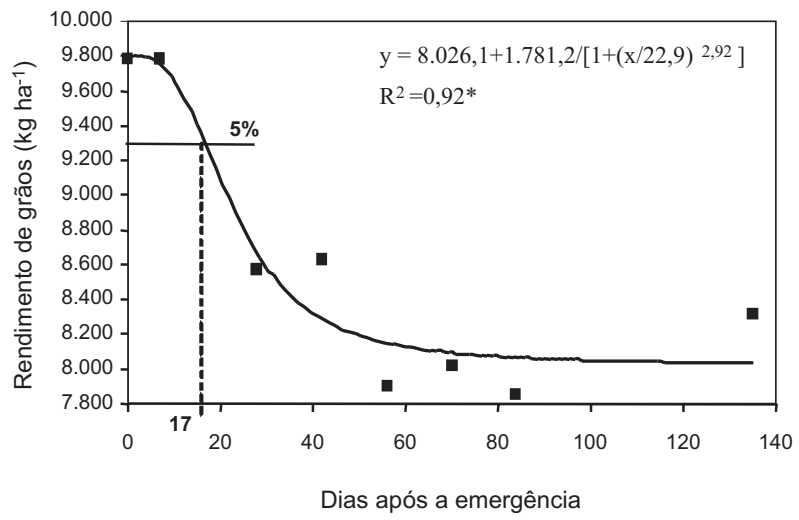

Figura 4 - Efeito do período de 0-7 dias de controle inicial e dos diferentes períodos de reinício de controle das plantas daninhas sobre o rendimento de grãos na cultura do milho. FEGA/PUCPR, Fazenda Rio Grande-PR, 2005/06.

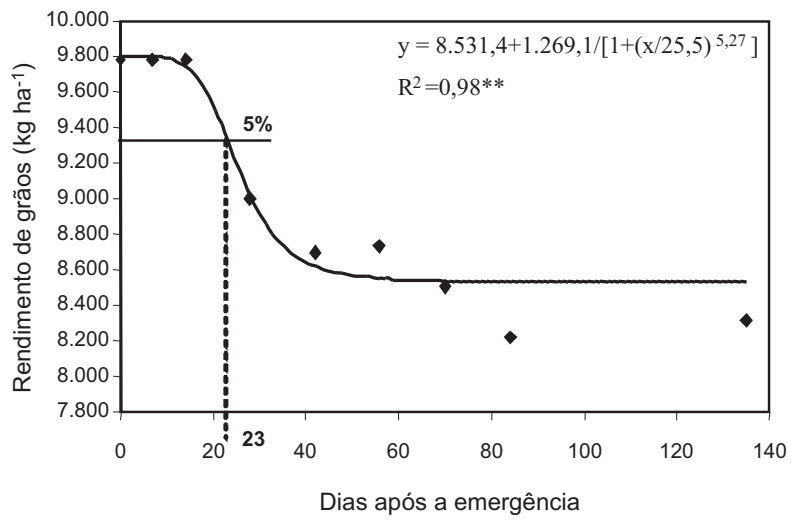

Figura 5 - Efeito do período de 0-14 dias de controle inicial e dos diferentes períodos de reinício de controle das plantas daninhas sobre o rendimento de grãos na cultura do milho. FEGA/PUCPR, Fazenda Rio Grande-PR, 2005/06. 


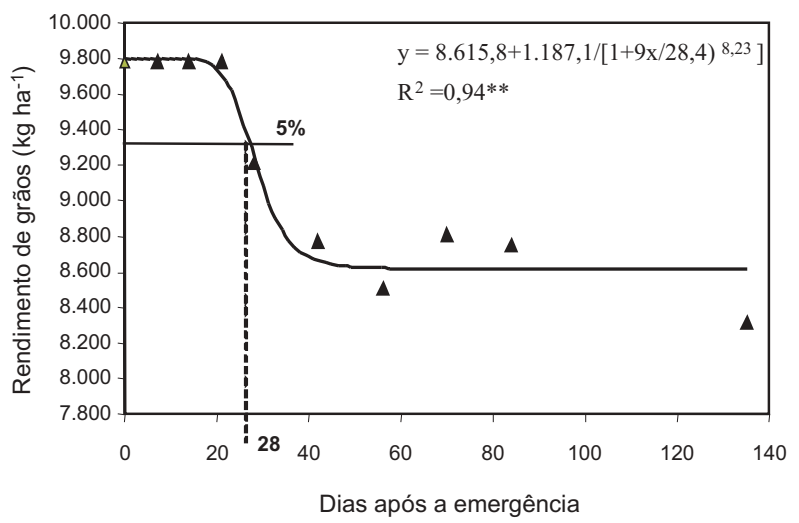

Figura 6 - Efeito do período de 0-21 dias de controle inicial e dos diferentes períodos de reinício de controle das plantas daninhas sobre o rendimento de grãos na cultura do milho. FEGA/PUCPR, Fazenda Rio Grande-PR, 2005/06

plantas serem jovens e ainda não ocorrer disputa pelos recursos do meio. À medida que a convivência aumentou, iniciou-se a interferência entre cultura e plantas daninhas. Isso ocorreu devido à competição interespecífica por água, luz e nutrientes, acarretando aumentos crescentes nas perdas de produtividade, $o$ que representou a fase de maior inclinação e linear da curva, verificando-se que cada indivíduo teve o máximo de impacto no rendimento de grãos da cultura.

À medida que a convivência se prolongou e com o aumento de densidade e acúmulo de massa seca pelas plantas infestantes, estas começaram a se sobrepor, começando a competir por luz e espaço; dessa forma, iniciou-se a competição intraespecífica e as perdas tenderam a se estabilizar, não mais influenciando a produtividade da cultura. Isso ocorre porque num determinado momento as plantas de milho já definiram seu potencial produtivo e não respondem mais à interferência das plantas daninhas. Nesse sentido, se estas forem eliminadas após esse momento, não haverá acréscimo de produtividade da cultura. No final da curva, com menor inclinação, verifica-se que o efeito de cada planta daninha, além das já existentes, foi pouco pronunciado, sendo essa resposta atribuída à redução e à sobreposição da área de influência de cada planta daninha. Os efeitos negativos das plantas daninhas na cultura variam conforme o grau de infestação, a espécie, o estádio fenológico da cultura e a duração do período de interferência. De modo geral, a relação entre infestação e rendimento econômico da cultura é não linear e segue um padrão sigmoidal. A não linearidade da resposta ocorre porque cada indivíduo da espécie daninha adicional, em infestação elevada, apresenta menos impacto relativo no desenvolvimento do milho do que quando as plantas daninhas estão em densidade relativamente baixa (Cousens, 1985).

Esse comportamento biológico representado pelo modelo sigmoidal da curva descrito pela equação logística possui um ponto de inflexão (coeficiente c), que representa o tempo para que ocorra $50 \%$ de redução no rendimento de grãos; a estabilização (coeficiente $a$ ), que representa o rendimento mínimo; e a perda de rendimento de grãos (coeficiente $b$ ). Assim, verifica-se que as reduções do rendimento de grãos foram mais intensas nos tratamentos em que os períodos iniciais de controle foram menores, como 0-0 e 0-7 DAE (Figuras 3 e 4), comparativamente àqueles de maior período inicial de controle, 0-14 e 0-21 DAE (Figuras 5 e 6), pois o coeficiente $b$ do modelo logístico (equação 1), que representa a perda de rendimento de grãos, foi maior para os períodos iniciais de controle de 0-0 e 0-7 DAE, com valores de $1.575,3$ e $1.781,2 \mathrm{~kg} \mathrm{ha}^{-1}$, respectivamente (Tabela 1).

Esses resultados sugerem que o controle de plantas daninhas na fase inicial do ciclo de desenvolvimento do milho é essencial para evitar perdas de rendimento de grãos, uma vez que as plantas daninhas que emergem na fase inicial do ciclo da cultura ocasionam muito mais perdas de rendimento do que aquelas que emergem em estádios mais avançados (Dew, 1972; O’Donovan et al., 1985; Hall et al., 1992; Knezevic et al., 1994; Murphy et al., 1996; Swanton et al., 1999).

Admitindo-se uma perda máxima aceitável de $5 \%$ no rendimento de grãos, o milho passou a ser prejudicado pela comunidade infestante a partir de $9 \mathrm{DAE}$, quando o período inicial de controle foi de 0-0 dia (Figura 3), ou seja, cultura e comunidade infestante emergiram simultaneamente, apresentando assim um periodo de $9 \mathrm{DAE}$, durante o qual a cultura pode conviver com as plantas daninhas sem que ocorra redução significativa na sua produtividade, ou seja, o periodo anterior à interferência (PAI), o que correspondeu ao estádio 
Tabela 1 - Coeficientes obtidos pelo modelo logístico aplicado ao rendimento de grãos do milho em função dos diferentes períodos iniciais e de reinício de controle das plantas daninhas. FEGA/PUCPR, Fazenda Rio Grande-PR, 2005/06

\begin{tabular}{|c|c|c|c|c|c|c|}
\hline $\begin{array}{c}\text { Período inicial de } \\
\text { controle }\end{array}$ & $a$ & $b$ & $c$ & $d$ & $\mathrm{R}^{2}$ & $\mathrm{~F}$ \\
\hline $0-0 \mathrm{DAE}^{1 /}$ & $8.209,2$ & $1.575,3$ & 11,4 & 3,72 & 0,98 & $51,3^{* *}$ \\
\hline $0-7 \mathrm{DAE}$ & $8.026,1$ & $1.781,2$ & 22,9 & 2,92 & 0,92 & $16,5^{*}$ \\
\hline $0-14 \mathrm{DAE}$ & $8.531,4$ & $1.269,1$ & 25,5 & 5,27 & 0,98 & $85,7^{* *}$ \\
\hline $0-21 \mathrm{DAE}$ & $8.615,8$ & $1.187,1$ & 28,4 & 8,23 & 0,94 & $33,5^{* *}$ \\
\hline
\end{tabular}

1/ dias após a emergência; ${ }^{* *}$ significativo a $1 \%$ de probabilidade; ${ }^{*}$ significativo a $5 \%$ de probabilidade.

$a$ - rendimento mínimo; $b$ - diferença entre rendimento máximo e mínimo, ou seja, a perda de rendimento de grãos; $c$ - tempo em dias em que ocorrem $50 \%$ de resposta no rendimento de grãos; $d$ - declividade da curva; $\mathrm{R}^{2}$ - coeficiente de determinação; $\mathrm{F}$ - valor da estatística $\mathrm{F}$.

fenológico V2 (duas folhas expandidas) do milho. Esses resultados estão de acordo com os obtidos em outros trabalhos que também indicaram o início do período crítico de prevenção da interferência no estádio fenológico de duas folhas totalmente expandidas (V2) (Defelice, 2001; Kozlowski, 2002; Evans et al., 2003b; Norsworthy \& Oliveira, 2004).

As razões da variabilidade observada em diversos trabalhos para o início e fim do periodo crítico de interferência devem-se a diferenças na fertilização nitrogenada, na composição da comunidade infestante, na densidade e na época de emergência das plantas daninhas nos diferentes locais (Hall et al., 1992; Halford et al., 2001; Evans et al., 2003a), nas características da espécie cultivada, cultivar, variáveis ambientais (Zimdahl, 1988; Swanton \& Weise, 1991), práticas culturais, época de semeadura e critérios estabelecidos com relação aos métodos utilizados para determinar o período crítico de interferência (Knezevic et al., 2002).

Com períodos iniciais crescentes de controle de 0-7, 0-14 e 0-21 DAE (Figuras 4, 5 e 6), no controle em pós-emergência com herbicida sem atividade residual (paraquat), verifica-se que os novos fluxos de emergência das plantas daninhas que ocorreram posteriormente ao controle inicial causaram reinfestação da cultura. Assim, o crescimento da comunidade infestante foi intenso a ponto de interferir na produtividade do milho e produzir um segundo PAI, chamado de período anterior à interferência subsequente (PAI-S), sendo este o período desde a aplicação do herbicida ou do controle das plantas infestantes até o momento em que a nova comunidade infestante (reinfestação) passou a interferir significativamente na produtividade da cultura (Pitelli, 2006).

Os resultados evidenciam a existência do PAI-S, e, em função dos períodos iniciais de controle de 0-7, 0-14 e 0-21 DAE, os PAI-S foram de 17, 24 e 28 DAE do milho, correspondendo aos estádios fenológicos V4, V6 e V7, respectivamente (Figuras 4, 5 e 6). Dessa forma, o início do período crítico de prevenção da interferência (PCPI) começa a partir do final do PAI e PAI-S e se caracteriza pelo período durante o qual é imprescindivel realizar o controle da comunidade infestante para que não ocorra redução significativa no rendimento de grãos. É importante salientar que, antes do final do PAI e PAI-S, mesmo se houver interferência, a cultura consegue se recuperar e manifestar seu potencial produtivo, porém, após o final do PAI e PAI-S, essa recuperação não ocorre a ponto de a cultura manifestar seu potencial produtivo.

De acordo com os resultados, observa-se que a interferência e os efeitos competitivos das plantas daninhas em milho são importantes na fase inicial do ciclo de desenvolvimento da cultura, pois, quanto mais precoce a germinação das plantas daninhas, mais cedo terão capacidade de competir pelos recursos do meio, prejudicando o rendimento final de grãos. Portanto, o controle das infestantes no início do ciclo de desenvolvimento é fundamental e necessário para se alcançar o máximo potencial de produção da cultura (Roush \& Radosevich, 1985; Zimdahl, 1988). O controle de plantas daninhas ao longo da estação de crescimento do milho com o mínimo de perdas de 
rendimento parece viável com uma simples aplicação de herbicida pós-emergente se a densidade das plantas daninhas for baixa, os fluxos subsequentes de germinação das infestantes forem mínimos e a época de aplicação do herbicida for apropriada.

Entretanto, quando as densidades das plantas daninhas forem altas, cuidados devem ser tomados para controle delas, impedindo a interferência com a cultura logo após a emergência, como evidenciado pelo início de período crítico de competição, que ocorreu tão precocemente quanto o observado nos primeiros dias após a emergência, quando o milho apresentava de duas (V2) a sete (V7) folhas totalmente expandidas, ou seja, entre 9 e 28 DAE. Nessa circunstância, poderia ser adotado um manejo químico com uso de herbicida residual aplicado na semeadura, um pós-emergente sem residual com aplicações sequenciais ou pós-emergente com residual, de forma a evitar a interferência das plantas daninhas emergidas em refluxo e, consequentemente, a redução do rendimento de grãos.

Apesar de o período crítico de interferência apresentar variações em função dos fatores citados anteriormente, a informação sobre o período crítico proporciona conhecimentos teóricas úteis com relação ao melhor momento para controle das plantas daninhas, com base em variáveis intrínsecas, em relação ao sistema de produção ou para uma comunidade infestante diversificada. Na prática, a partir de certa intensidade, os efeitos da interferência são irreversíveis, não havendo recuperação do desenvolvimento ou da produtividade da cultura após a retirada do estresse causado pela presença das plantas daninhas (Kozlowski, 2002).

A definição das situações em que haverá o PAI-S e em qual este será precoce ou tardio no restante do ciclo da cultura é fundamental para o planejamento do número e das épocas de aplicação do herbicida sem ação residual ou do estabelecimento de combinações de produtos ou estratégias de manejo.

Os dados de produtividade confirmam os efeitos prejudiciais da interferência das plantas daninhas sobre a cultura, de modo que a convivência com essas plantas prejudicou significativamente o rendimento de grãos do milho. No tratamento sem controle das plantas daninhas, houve redução de $15 \%$ na produtividade de grãos em relação à testemunha capinada. Esses resultados concordam com os de trabalhos anteriores, em que se constataram reduções entre 10 e $91 \%$ no rendimento de grãos devido à interferência das plantas daninhas (Wilson \& Westra, 1991; Spader \& Vidal, 2000b; Harrison et al., 2001; Massinga et al., 2001; Hellwig et al., 2002; Kozlowski, 2002; Cathcart \& Swanton, 2004; Alford et al., 2005; Cox et al., 2006; Williams, 2006).

Diante das condições experimentais e pelos resultados obtidos, pode-se concluir que: um controle inicial da comunidade infestante é importante para reduzir a densidade das espécies infestantes e sua capacidade de acúmulo de matéria seca e de mobilização de recursos do meio e, portanto, seu poder de interferência competitiva sobre a cultura do milho; o controle de plantas daninhas na fase inicial do ciclo de desenvolvimento do milho é essencial para evitar perdas de rendimento de grãos; e houve ocorrência do PAI-S no milho mesmo com períodos iniciais de controle de 21 dias. O PAI-S dos períodos iniciais de controle (0-7, 0-14 e 0-21 DAE) ocorreu aos 17, 24 e 28 DAE do milho, correspondendo aos estádios fenológicos V4, V6 e V7, respectivamente.

\section{LITERATURA CITADA}

ALFORD, J. L. et al. Broadleaf signalgrass (Brachiaria platyphylla) interference in corn. Weed Sci., v. 53, n. 1, p. 97-100, 2005.

CATHCART, R. J.; SWANTON, C. J. Nitrogen and green foxtail (Setaria viridis) competition effects on corn growth and development. Weed Sci., v. 52, n. 6, p. 1039-1049, 2004.

COX, W. J.; HAHN, R. R.; STACHOWSKI, P. J. Time of weed removal with glyphosate affects corn growth and yield components. Agron. J., v. 98, n. 2, p.349-353, 2006.

COUSENS, R. A simple model relating yield loss to weed density. Ann. Appl. Biol., v. 107, n. 2, p. 239-252, 1985.

DEFELICE, M. Critical period of weed interference in corn and proper timing of herbicide programs. 2001. Disponível em: <http://www.pioneer.com/usa/ crop_management/national/timing_cornherb.html $>$. Acesso em: 18 maio 2008 .

Planta Daninha, Viçosa-MG, v. 27, n. 3, p. 481-490, 2009 
DEW, D. A. An index of competition for estimating crop loss due to weeds. Can. J. Plant Sci., v. 52, n. 6, p. 921-927, 1972 .

EVANS, S. P. et al. Nitrogen application influences the critical period for weed control in corn. Weed Sci., v. 51, n. 3, p. $408-417,2003 a$.

EVANS, S. P. et al. Influence of nitrogen and duration of weed interference on corn growth and development. Weed Sci., v. 51, n. 4, p. $546-556,2003$ b.

GLAT, D. Perspectivas do milho para 2002. Plantio Direto, v. 69, n. 1, p. $15-17,2002$.

HALFORD, C. et al. Critical period of weed control in no-till soybean and corn. Weed Technol., v. 15, n. 4, p. 737-744, 2001.

HALL, M. R.; SWANTON, C. J.; ANDERSON, G. W. The critical period of weed control in grain corn (Zea mays).

Weed Sci., v. 40, n. 4, p. 441-447, 1992

HARRISON, S. K. et al. Competition and fecundity of giant ragweed in corn. Weed Sci., v. 49, n. 2, p. 224-229, 2001.

HELLWIG, K. B.; JOHNSON, W. G.; SCHARF, P. C. Grass weed interference and nitrogen accumulation in no-tillage corn Weed Sci., v. 50, n. 6, p. 757-762, 2002.

KNEZEVIC, S. Z. et al. Critical period for weed control: the concept and data analysis. Weed Sci., v. 50, n. 6, p. 773-786, 2002.

KNEZEVIC, S. Z; WEISE, S. F.; SWANTON, C. J. Interference of redroot pigweed (Amaranthus retroflexus) in corn (Zea mays). Weed Sci., v. 42, n. 4, p. 568-573, 1994.

KOZLOWSKI, L. A. Período crítico de interferência das plantas daninhas na cultura do milho baseado na fenologia da cultura. Planta Daninha, v. 20, n. 3, p. 365-372, 2002.

MASSINGA, R. A. et al. Interference of Palmer amaranth in corn. Weed Sci., v. 49, n. 2, p. 202-208, 2001

MORTENSEN, D. A.; BASTIAANS, L.; SATTIN, M. The role of ecology in the development of weed management systems: an outlook. Weed Res., v. 40, n. 1, p. 49-62, 2000.

MURPHY, S. D. et al. Effect of planting patterns and inter-row cultivation on competition between corn ( $\mathrm{Zea}$ mays) and late emerging weeds. Weed Sci., v. 44, n. 6, p. 865-870, 1996.

NORSWORTHY, J. K.; OLIVEIRA, M. J. Comparison of the critical period for weed control in wide- and narrow-row corn. Weed Sci., v. 52, n. 5, p. 802-807, 2004
O'DONOVAN, J. T. et al. Influence of the relative time of emergence of wild oat (Avena fatua) on yield loss of barley (Hordeum vulgare) and wheat (Triticum aestivum). Weed Sci., v. 33, n. 5, p. 498-503, 1985.

PITELLI, R. A. O período anterior à interferência subseqüente (PAIS), uma nova abordagem para o manejo de plantas daninhas em culturas geneticamente modificadas para tolerância aos herbicidas não seletivos e sem residual. In: CONGRESSO BRASILEIRO DA CIÊNCIA DAS PLANTAS DANINHAS, 25., 2006, Brasília. Convivendo com as plantas daninhas Resumos... Brasília: SBCPD/UNB/ Embrapa Cerrados, 2006. p. 125.

PITELLI, R. A. Interferência de plantas daninhas em culturas agrícolas. Inf. Agropec., v. 11, n. 129, p. 16-27, 1985

PITELLI, R. A.; DURIGAN, J. C. Terminologia para períodos de controle e de convivência de plantas daninhas em culturas anuais e bianuais. In: CONGRESSO BRASILEIRO DE HERBICIDAS E PLANTAS DANINHAS, 15., 1984, Belo Horizonte. Resumos... Piracicaba: AUGEGRAF, 1984. p. 37.

RADOSEVICH, S. R.; HOLT, J. S. Weed ecology: Implications for vegetation management. New York: John Wiley \& Sons, 1984. 263 p.

ROUSH, M. L.; RADOSEVICH, S. R. Relationships between growth and competitiveness of four annual weeds. J. Appl. Ecol., v. 22, n. 6, p. 895-905, 1985.

SPADER, V.; VIDAL, R. A. Interferência de Brachiaria plantaginea sobre características agronômicas, componentes do rendimento e produtividade de grãos do milho. Planta Daninha, v. 18 , n. 3, p. $465-470,2000$ b

SWANTON, C. J. et al. Weed thresholds: theory and applicability. J. Crop Prod., v. 2, n. 1, p. 9-29, 1999

SWANTON, C. J.; WEISE, S. F. Integrated weed management: the rationale and approach. Weed Technol., v. 5 , n. 3 , p. $648-656,1991$

VAN ACKER, R. C.; SWANTON, C. J.; WEISE, S. F. The critical period of weed control in soybean (Glycine max). Weed Sci., v. 41, n. 2, p. 194-200, 1993.

WILLIAMS, M. M. II. Planting date influences critical period of weed control in sweet corn. Weed Sci., v. 54, n. 5, p. $928-933,2006$.

WILSON, R. G.; WESTRA, P. Wild proso millet (Panicum miliaceum) interference in corn (Zea mays). Weed Sci., v. 39, n. 2, p. 217-220, 1991.

ZIMDAHL, R. L. The concept and application of the critical weed-free period. In: ALTIERI, M. A.; LIEBMAN, M. (Eds.) Weed management in agroecosystems: ecological approaches. Boca Raton: CRC, 1988. p. 145-155. 